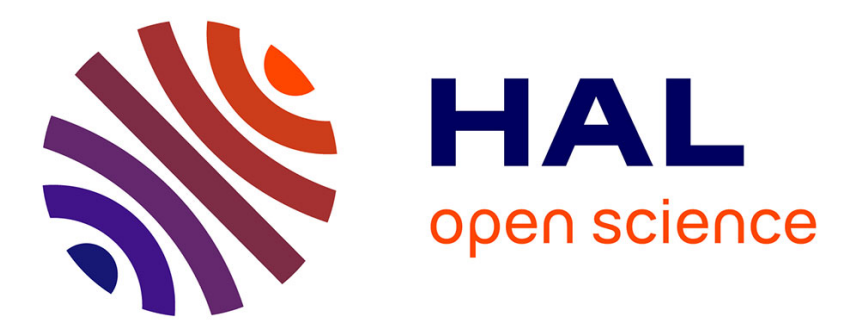

\title{
Aerodynamic wall pressure measurement using a high temperature gradient Pirani micro-sensor
}

Cécile Ghouila-Houri, Munique Kazar Mendes, Thomas Arnoult, Romain

Viard, Quentin Gallas, Eric Garnier, Alain Merlen, Abdelkrim Talbi, Philippe

Pernod

\section{To cite this version:}

Cécile Ghouila-Houri, Munique Kazar Mendes, Thomas Arnoult, Romain Viard, Quentin Gallas, et al.. Aerodynamic wall pressure measurement using a high temperature gradient Pirani micro-sensor. 2020 IEEE SENSORS, Oct 2020, Rotterdam, Netherlands. pp.1-3, 10.1109/SENSORS47125.2020.9278842 . hal-03187073

\section{HAL Id: hal-03187073 \\ https://hal.science/hal-03187073}

Submitted on 31 Mar 2021

HAL is a multi-disciplinary open access archive for the deposit and dissemination of scientific research documents, whether they are published or not. The documents may come from teaching and research institutions in France or abroad, or from public or private research centers.
L'archive ouverte pluridisciplinaire HAL, est destinée au dépôt et à la diffusion de documents scientifiques de niveau recherche, publiés ou non, émanant des établissements d'enseignement et de recherche français ou étrangers, des laboratoires publics ou privés. 


\title{
Aerodynamic wall pressure measurement using a high temperature gradient Pirani micro-sensor
}

\author{
C. Ghouila-Houri ${ }^{1}$ IEEE Member, M. Kazar-Mendes ${ }^{1}$, T. Arnoult ${ }^{1}$, R. Viard ${ }^{2}$, Q. Gallas ${ }^{3}$, E. Garnier ${ }^{4}$, A. Merlen ${ }^{1}$, \\ A. Talbi ${ }^{1}$ IEEE Member, P. Pernod ${ }^{1}$ \\ ${ }^{1}$ Univ. Lille, CNRS, Centrale Lille, Yncréa ISEN, Univ. Polytechnique Hauts-de-France, UMR 8520 IEMN, F-59000 Lille, \\ France \\ ${ }^{2}$ JMH Conception F- 68100 Mulhouse, France \\ ${ }^{3}$ Univ. Lille, CNRS, ONERA, Arts et Metiers Institute of Technology, Centrale Lille, UMR 9014, Laboratoire de Mécanique \\ des fluides de Lille-Kampé de Fériet, F-59000 Lille, France \\ ${ }^{4}$ DAAA, ONERA The French Aerospace Lab, Meudon, F-92190, France
}

\begin{abstract}
This paper presents and discusses the first demonstration of aerodynamic wall pressure measurement using a thermal Pirani effect based micro-sensor. The thermal micro-sensor is designed as a suspended micro-hot-wire separated from the substrate by a nanoscale gap, and mechanically supported by perpendicular micro-bridges. The micro-sensor was calibrated for pressure measurement from $10 \mathrm{kPa}$ to $800 \mathrm{kPa}$. It was then used as aerodynamic wall pressure sensor in a turbulent boundary layer wind tunnel and successfully measured the $1.1 \mathrm{kPa}$ depression occurring in the wind tunnel when the flow velocity goes up to $40 \mathrm{~m} / \mathrm{s}$. (Abstract)
\end{abstract}

Keywords-Pirani sensor; Pressure sensor; MEMS; Aerodynamic wall pressure.

\section{INTRODUCTION}

Aerodynamic turbulent flows are characterized by a complex behavior with multiple vortices of varying size, intensity and frequency. The complexity of turbulence lies in the Navier-Stockes equations that can only be solved in simple geometries and low turbulent flows (low Reynolds number flows) [1]. For complex geometries and highly turbulent flows (high Reynolds number flows), computer simulations require experimental data. More precisely, two quantities are of great interest in turbulence equations: the wall shear stress and the wall pressure. Therefore, engineers and scientists have worked on the development of wall shear stress and wall pressure sensors for aerodynamic applications [2], [3].

One particularity of turbulent flows is that spatial and temporal scales of turbulence structures decrease when the Reynolds number increases. The need is thereby of small and fast sensors and MEMS (Micro Electro Mechanical Systems) technologies logically appeared as a potential solution to address this issue. The measurement of wall shear stress using MEMS devices was, and is still, vastly investigated, with technologies using various physical principles: from floating element based capacitive sensors to thermal sensors [4]. Our group in IEMN (Institute of Electronics, Microelectronics and Nanotechnology) designed, fabricated, characterized and calibrated bidirectional wall shear stress thermal micro-sensors ([5], [3]), based on a suspended hotwire microstructure.

For the measurement of wall pressure fluctuations, most technologies are based on a membrane design. The membrane is deformed due to the pressure fluctuations and the transducers either detects the stress using piezoresistive effect as in [6] or the deflection using capacitive measurement [7]. In each case, the measurement of pressure involves a movable mechanical part, sensitive to structure vibrations.

On the contrary, the Pirani effect exploits thermal transfers to measure the absolute pressure. Indeed, the gas thermal conductivity is pressure dependent. Consequently, Pirani sensors are composed of a hot-wire and a heat sink, and they measure the thermal transfer from the hot-wire to the substrate through the gas present in the gap between them [8]. When the pressure is high, the heat transfer, which is realized by the collision of gas molecules, is fully efficient. When pressure lowers, the mean free path of gas molecules increases. At the so-called pressure of transition, the mean free path of gas molecules becomes similar to the gap. Consequently, the heat transfer by collision becomes less efficient and the thermal conductivity decreases until the hot-wire is thermally isolated from the substrate [9]. Thus, no movable part is involved in the working principle of such sensors. However, Pirani sensors are usually used for vacuum pressure applications [10] because for the measurement of pressure near the atmospheric pressure, the gap needs to be at nanoscales [11]. Our group developed a MEMS Pirani sensor with a nanoscale gap demonstrating a maximum of sensitivity around atmospheric pressure [9].

In the present work, we investigated the utilization of this Pirani micro-sensor for aerodynamic wall pressure measurement in a turbulent boundary layer wind tunnel.

This paper will be divided into two main parts. Firstly, we will introduce the micro-sensor particular design achieving a high temperature gradient, a large heat exchange area and a nanoscale gap. We will also present the calibration of the Pirani sensor for a wide range of pressure going from $10 \mathrm{kPa}$ to $800 \mathrm{kPa}$. Secondly, we will present the integration of the Pirani micro-sensor in wind tunnel facilities. In this part, we will describe and discuss the aerodynamic wall pressure measurement performed in the wind tunnel. 


\section{THE PIRANI MICRO-SENSOR DESIGN AND CALIBRATION}

\section{A. The design}

As mentioned before, Pirani sensors are usually composed of a hot-wire suspended over the substrate with a micro-bridge design anchored to the substrate at each extremity [8]. In our work, the design is slightly different. The micro-sensor is designed as a $1 \mathrm{~mm}$ long hot-wire based microstructure which is suspended over the substrate and mechanically supported by perpendicular silicon dioxide micro-bridges (Fig. 1 (a)). With such design, the present micro-sensor acts as multiple micro-Pirani gauges, which are about $10 \mu \mathrm{m}$ long, anchored to two micro-bridges on extremities, and placed in series to reach $1 \mathrm{~mm}$ long. The gap between the hot-wire and the substrate is height-controlled and can be reduced up to $100 \mathrm{~nm}$. Consequently, the microsensor reach both a nanoscale gap and a large heat exchange area that improves the signal to noise ratio and the dynamic range of the measure.

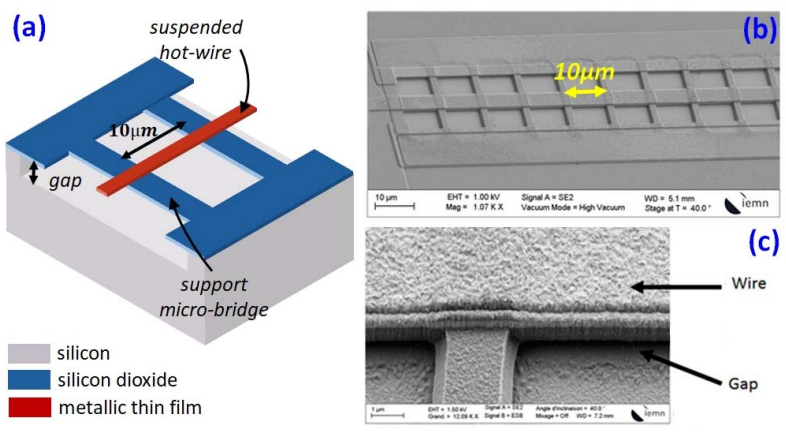

Fig 1: (a) Schematic of the Pirani micro-sensor (not to scale) (b) SEM picture of the fabricated micro-sensor (c) Zoom on the gap (SEM

The micro-sensor was fabricated in the IEMN cleanroom facilities, using conventional surface micromachining techniques as described in [9]. Figure 1 (b) and (c) display Scanning Electron Microscopy (SEM) pictures of the fabricated micro-sensor. In Figure 1 (b), one can see the series of $10 \mu \mathrm{m}$ long micro-Pirani gauges shaping the $1 \mathrm{~mm}$ long hot-wire. In Figure 1 (c), the nanogap is visible: both the wire and the micro-bridges are suspended over the substrate.

The microstructure allowed then a nanoscale gap but with a $1 \mathrm{~mm}$ long hot-wire which allows to have a large heat exchange area and a high temperature gradient $\left(2^{\circ} \mathrm{C} / \mathrm{mW}\right.$ [9]) for high signal to noise ratio, compared to nanowires.

\section{B. Calibration of the device}

The micro-sensor was calibrated in a pressure-controlled chamber (Fig. 2 (a)). The pressure was controlled using a PPC4 Fluke Pressure calibrator.

The micro-sensor works in Constant Temperature (CT) mode: the heating current is electronically regulated to maintain the wire temperature constant. We calibrated the micro-sensor for pressure going from $10 \mathrm{kPa}$ to $800 \mathrm{kPa}$. The dynamic range considered here is far larger than the needed range in aerodynamics. Nonetheless, as shown in Figure 2 (b), the micro-sensor has not reached its saturation limits, neither at high pressure nor at low pressure. The maximum of sensitivity is reached for $110 \mathrm{kPa}$ [9]. The direction of current variation can be noted: it increases with over pressure and decreases with depression.

(a)

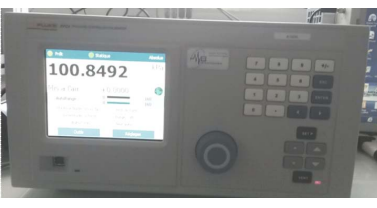

PPC4 Fluke calibrator

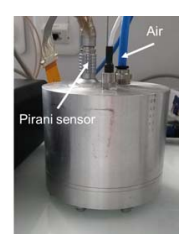

Pressure chamber

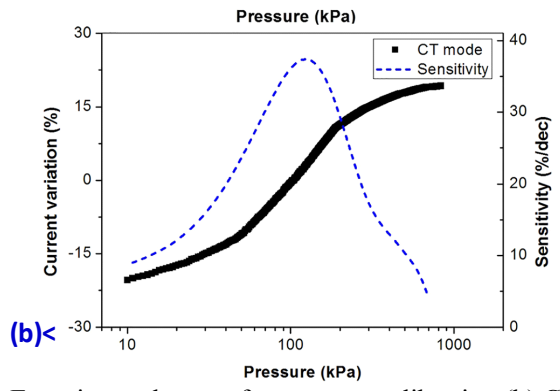

Fig. 2: (a) Experimental set up for pressure calibration (b) Calibration of the Pirani micro-sensor [9]

\section{AERODYNAMIC WALL PRESSURE MEASUREMENTS}

\section{A. Integration in wind tunnel}

Wind tunnel experiments were performed in the ONERA Lille Turbulent Boundary Layer wind tunnel (Fig. 3 (a)). The wind tunnel test section is $30 \mathrm{~cm}$ by $30 \mathrm{~cm}$ and the mainstream flow velocity reaches a maximum of $40 \mathrm{~m} / \mathrm{s}$. The Pirani micro-sensor was packaged on a support and contacts were recovered using wire bonding (Fig. 3 (b)).

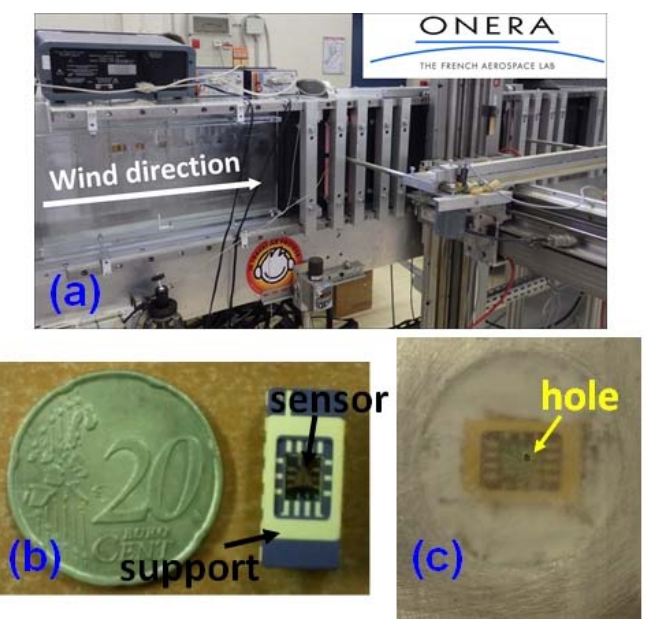

Fig3: (a) ONERA Lille wind tunnel (b) Micro-Pirani Sensor wire bonded on a support (c) Integration in the wind tunnel wall with a rigid cover avoiding convective heat transfer

The integration of the micro-sensor in the wind tunnel wall needed however the addition of a rigid cover with a hole, allowing pressure measurement while avoiding convective heat transfer. Indeed, the micro-sensor is based 
on thermal principle as thermal flow sensors and is therefore sensitive to wall shear stress by convective heat transfer as described in [12]. However, it is simple to know if the microsensor measures pressure or wall shear stress. Indeed, with the increasing flow velocity, the wall pressure decreases whereas the wall shear stress increases. As regards the micro-sensor operation, the heating current increases when the wall shear stress increases [12] whereas it decreases when measuring a depression.

\section{B. Results}

We realized two experiments: first we measured the variation of heating current of the Pirani micro-sensor with the flow velocity. Then we replaced the Pirani micro-sensor by a membrane based commercial piezo-resistive pressure sensor and realized the measurements again as reference measurements. Thereby we could compare the two results. In Figure 4, we displayed the measured variation of pressure versus the mainstream flow velocity $U_{\infty}$ for both the reference sensor and the Pirani micro-sensor. For the latter, we used the calibration curve obtained in Figure 2 (b) to convert the variation of heating current in pressure variation.

The results presented in Figure 4 show that both sensors measure almost the same diminution of pressure with the flow velocity, with up to $-1.1 \mathrm{kPa}$ for $40 \mathrm{~m} / \mathrm{s}$. This is the first demonstration of aerodynamic wall pressure measurement using a thermal Pirani sensor. Further work will investigate the measurement of the dynamic wall pressure fluctuations using the thermal Pirani micro-sensor.

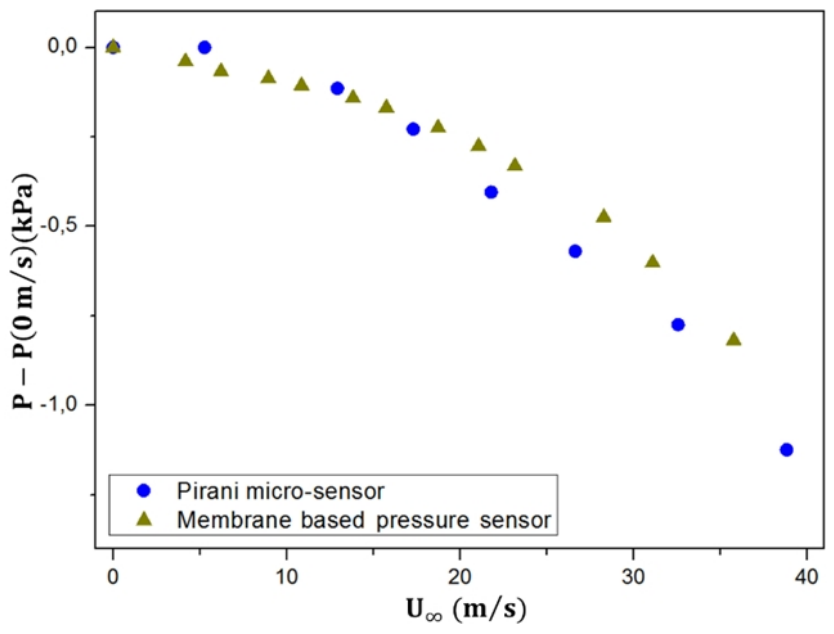

Fig 4: Pressure variation measured by the Pirani micro-sensor versus flow velocity and comparison with a reference pressure sensor

\section{CONCLUSION}

In this paper, we presented the first demonstration of aerodynamic wall pressure measurement using a high temperature gradient Pirani based micro-sensor. The microsensor was designed with a nanoscale gap and a large heat exchange area for obtaining both maximum sensitivity at atmospheric pressure and high signal to noise ratio. It was fabricated in the IEMN cleanroom using CMOS compatible micromachining techniques, allowing future integration in microelectronic chip. The micro-sensor was integrated in a wind tunnel wall and we measured the diminution of pressure with the increasing mainstream flow velocity. The comparison of the obtained result to a reference sensor demonstrated the ability of the Pirani micro-sensor to measure aerodynamic wall pressure. Future work will investigate the dynamic calibration of the micro-sensor and the use of the micro-sensor to measure the wall pressure fluctuations in various fluidic configurations (flat plate, separated flow...).

\section{ACKNOWLEDGMENT}

This work was funded by the French National Research Agency (ANR) in the framework of the ANR ASTRID "CAMELOTT" Project. It is supported by the regional platform CONTRAERO in the framework of the CPER ELSAT 2020 Project. The authors also thank RENATECH, the French national nanofabrication network, and FEDER.

\section{REFERENCES}

[1] L. Löfdahl et M. Gad-el-Hak, "MEMS applications in turbulence and flow control », Progress in Aerospace Sciences, vol. 35, $\mathrm{n}^{\circ} 2$, p. 101 203, févr. 1999, doi: 10.1016/S0376-0421(98)00012-8.

[2] L. Löfdahl et M. Gad-el-Hak, «MEMS-based pressure and shear stress sensors for turbulent flows », Measurement Science and Technology, vol. 10, $\mathrm{n}^{\circ} 8$, p. 665, 1999.

[3] C. Ghouila-Houri et al., «Unsteady flows measurements using a calorimetric wall shear stress micro-sensor », Exp Fluids, vol. 60, $\mathrm{n}^{\circ}$ 4, p. 67, mars 2019, doi: 10.1007/s00348-019-2714-5.

[4] C. Ghouila-Houri et al., «High temperature gradient calorimetric wall shear stress micro-sensor for flow separation detection », Sensors and Actuators A: Physical, vol. 266, p. 232 241, oct. 2017, doi: 10.1016/j.sna.2017.09.030.

[5] C. Ghouila-Houri et al., « High temperature gradient micro-sensor for wall shear stress and flow direction measurements », Appl. Phys. Lett., vol. 109, n 24, p. 241905, déc. 2016, doi: 10.1063/1.4972402.

[6] A. Berns, U. Buder, E. Obermeier, A. Wolter, et A. Leder, «AeroMEMS sensor array for high-resolution wall pressure measurements », Sensors and Actuators A: Physical, vol. 132, $\mathrm{n}^{\circ} 1, \mathrm{p}$. 104 111, nov. 2006, doi: 10.1016/j.sna.2006.04.056.

[7] M. Zagnoni et al., «A non-invasive capacitive sensor strip for aerodynamic pressure measurement ", Sensors and Actuators A: Physical, vol. 123, $\mathrm{n}^{\circ}$ Supplement C, p. 240 248, sept. 2005, doi: 10.1016/j.sna.2005.03.049.

[8] F. Santagata, E. Iervolino, L. Mele, A. W. van Herwaarden, J. F. Creemer, et P. M. Sarro, «An analytical model and verification for MEMS Pirani gauges », Journal of Micromechanics and Microengineering, vol. 21, $\mathrm{n}^{\circ} 11$, p. 115007, nov. 2011, doi: 10.1088/0960-1317/21/11/115007.

[9] C. Ghouila-Houri et al., « High temperature gradient nanogap-Pirani micro-sensor with maximum sensitivity around atmospheric pressure », Appl. Phys. Lett., vol. 111, n 11, p. 113502, sept. 2017, doi: 10.1063/1.4995364.

[10] M. Grau, F. Völklein, A. Meier, C. Kunz, I. Kaufmann, et P. Woias, «Optimized MEMS Pirani sensor with increased pressure measurement sensitivity in the fine and rough vacuum regimes $»$, Journal of Vacuum Science \& Technology A: Vacuum, Surfaces, and Films, vol. 33, no 2, p. 021601, nov. 2014, doi: 10.1116/1.4902340.

[11] K. Khosraviani et A. M. Leung, «The nanogap Pirani-a pressure sensor with superior linearity in an atmospheric pressure range », Journal of Micromechanics and Microengineering, vol. 19, $\mathrm{n}^{\circ} 4, \mathrm{p}$. 045007, avr. 2009, doi: 10.1088/0960-1317/19/4/045007.

[12] C. Ghouila-Houri et al., «Robust thermal microstructure for designing flow sensors and pressure sensors ", in 2017 IEEE SENSORS, oct. 2017, p. 1 3, doi: 10.1109/ICSENS.2017.8233961. 